\title{
Account
}

\section{Mesoporous Thin Films with Accessible Pores from Surfaces}

\author{
U-Hwang Lee, Min-Hye Kim, and Young-Uk Kwon* \\ Department of Chemistry, BK-21 School of Molecular Science, Center for Nanotubes and Nanostructured Composites, \\ and SKKU Advanced Institute of Nanotechnology, Suwon 440-746, Korea. E-mail: ywkwon@skku.edu \\ Received February 20, 2006
}

\begin{abstract}
Among the many forms of mesoporous materials, thin films are important for the potential applications of this class of materials. Compared with the powder forms, however, there has been relatively little work done on thin films probably because of the lack of suitable and generalized synthetic mechanisms established. In this account, we will review the issues on mesoporous thin films with emphasis on the necessity of forming films with accessible pores from the film surfaces and on mesoporous thin films with metal oxides other than silica. Various methods that have been tried to utilize mesoporous thin films with accessible pores as templates for the synthesis of nanostructured materials are reviewed with the emphasis on the advantages of the electrochemical deposition technique.
\end{abstract}

Key Words : Mesoporous, Thin films, Pore accessibility

\section{Introduction}

Mesoporous materials with ordered pores of a few nanometers have attracted a great deal of interests recent years since the first paper by the Mobile group has appeared in 1992. ${ }^{1,2}$ A wide range of research activity is underway including the fundamental aspects such as formation mechanism and structures, and forefront applications such as nanocatalysis and fabrication of nanomaterials. Many review papers have appeared to cover these dynamic and fast-growing research topics. ${ }^{3-8}$

Most of the studies have been performed on the powdery forms. On the contrary, far less attention has been paid to the thin film forms of this class of materials. This is probably because the synthetic techniques of thin films have been less-well developed. However, it is obvious that the thin films of mesoporous materials may have several advantages over the powdery forms when one tries to utilize the ordered porous structures. For example, one may imagine membranes and filters made of mesoporous thin films that may find applications in separation of biomaterials. Mesoporous thin films may host various types of nanomaterials with nanometer length scale of spatial resolution, which may eventually develop into nanodevices. Because of such potentials, mesoporous thin films have been attracting growing attentions since the first report in $1996 .{ }^{9}$ Literature search on Sci-Finder with the key words "mesoporous thin films" yielded over 600 counts until 2005, demonstrating the fast-growing nature of this field. Various aspects of the mesoporous thin films have been studied including the formation mechanisms and the roles of synthetic parameters, type of wall materials, surface modifications and functionalization, physical and chemical properties, and applications. There are several review papers on these and related topics. ${ }^{10-18}$ Topics such as formation mechanisms of mesoporous thin films, silica or organosilica mesoporous thin films are well documented and the readers referred to the literature.

The perspective of forming mesoporous materials into thin films and of applying them as membranes or templates for the synthesis of nanostructured materials raises a few requirements that pose synthetic challenges. First, the films must be continuous and free of crack. Second, the pores of the thin films must be accessible, preferably, from the film surface. Third, mesoporous thin films with non-silica walls are highly desirable in order to process into functional materials. In general, the thin film materials undergo shrinkage during calcination, inducing tension inside the
U-Hwang Lee was born in Seoul, Korea in 1976. He received his B.S. (2001) and M.S. (2003) degrees (both in Chemistry) from Sungkyunkwan University, and is currently a Ph.D. candidate in Chemistry at Sungkyunkwan University. His research interests are focused on the syntheses and applications of mesoporous silica thin films.

Min-Hye Kim was born in Seoul, Korea in 1980. She received her B.S. degree (Chemistry) in 2003 from Sungkyunkwan University. She is a Ph.D candidate in Chemistry at Sungkyunkwan University. Her research topic is mainly focused on solar cells, especially employing mesoporous titania thin films.
Young-Uk Kwon was born in Seoul, Korea in 1961. He received a B.S. degree in Chemistry at Seoul National University (1984), and M.S. (1987) and Ph.D. (1991) degrees both in Inorganic Chemistry at Iowa State University, under the supervision of Professor John D. Corbett. In 1991. 2.-1992. 8., he worked at AT\&T Bell Laboratories, Murray Hills, NJ, USA as a postdoctal technical staff and, then, joined the faculty of Chemistry at Sungkyunkwan University. His research interests are on synthesis and characterization of various inorganic materials including mesoporous thin films, intercluster salt compounds, solid state metal oxides. 


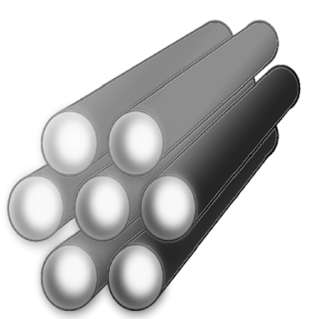

(a)

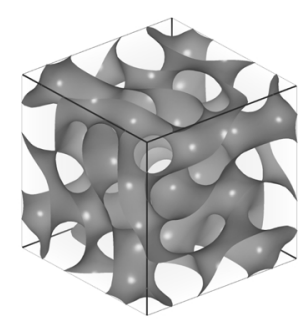

(b)

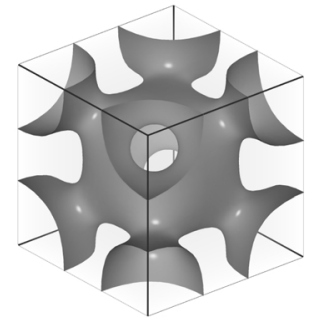

(c)

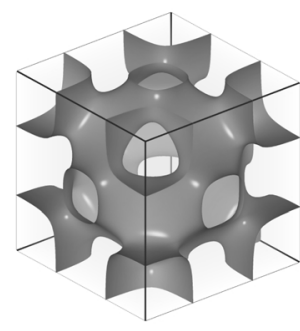

(d)

Figure 1. Common structures found in mesoporous materials. (a) hexagonal and cubic (b) $\operatorname{Ia} \overline{3} \mathrm{~d}$, (c) $\operatorname{Im} \overline{3} \mathrm{~m}$, and (d) $P \mathrm{~m} \overline{3} \mathrm{~m}$ structures.

film materials and cause cracks. The shrinkage problem is a serious one because of the removal of the template organic molecules and the condensation of the wall materials both contribute to the shrinkage, resulting in large degree of shrinkage. However, this problem can be solved by controlling the process parameters especially during the calcination and film-drying steps. On the other hand, this problem generally limits the thickness of the films to be formed less than a few hundred nanometers.

The second and third requirements are more difficult than the first one, and these are the subjects of the present account. As may be well-known, mesoporous materials form varied pore structures including hexagonal $(\mathrm{p} 6 \mathrm{~mm})$, cubic (Ia $\overline{3} \mathrm{~d}, \operatorname{Im} \overline{3} \mathrm{~m}$, and $\mathrm{Pm} \overline{3} \mathrm{~m}$ ), and disordered structures (Figure 1). Although the hexagonal structure is the most popular, mainly because of its intuitively simple structure and the easiest synthetic procedure, this structure has an inherent drawback in terms of pore accessibility when obtained as thin films because the interfacial energy between the substrate surface and the film materials make the pores lie parallel to the substrate surface. In order to better use the mesoporous thin films, many researchers have sought methods to synthesize with non-silica materials. There are two major directions in the synthesis of non-silica mesoporous materials, oxides of non-silicon and organically modified silica. While the latter itself is an attractive subject, especially when considering the possibility of functionalizing with chemicals or biologically active materials, this subject has been well accounted for in a review by Sanchez et al. ${ }^{19}$ Therefore, we will focus more on the other topic, namely, mesoposous thin films made of oxides of nonsilicon, although some examples of mesoporous silica films that have been used as templates will be also discussed.

\section{Wall Materials and Formation Process}

In general, the formation of mesoscopic ordering of mesoporous materials is explained by the self-assembly of the structure directing agents with inorganic precursors. In addition to the cationic surfactants such as cetyltrimethylammonium bromide (CTAB) that has been used for the first example of mesoporous silica, non-ionic surfactants are being used as the structure directing agents. Most widely used non-ionic surfactants include the Pluronic type $\left(\mathrm{EO}_{\mathrm{m}} \mathrm{PO}_{\mathrm{n}} \mathrm{EO}_{\mathrm{m}}, \mathrm{EO}=\right.$ ethylene oxide, $\mathrm{PO}=$ propylene oxide $)$ and Brij type $\left(\mathrm{C}_{\mathrm{m}} \mathrm{H}_{2 \mathrm{~m}+1} \mathrm{EO}_{\mathrm{n}}\right)$. They are often referred with their commercial names such as $\mathrm{P} 123\left(\mathrm{EO}_{20} \mathrm{PO}_{70} \mathrm{EO}_{20}\right)$, F127 ( $\left.\mathrm{EO}_{106} \mathrm{PO}_{70} \mathrm{EO}_{106}\right)$, and Brij-58 $\left(\mathrm{C}_{16} \mathrm{H}_{33} \mathrm{EO}_{20}\right)$, and we will use such nomenclature here.

Silica is the first choice material for the synthesis of mesoporous materials both in thin film and powder forms, the reason being the relatively slow hydrolysis and condensation reaction rates of silica species even in water, which enables one to control the reaction kinetics and, thereby, to control the morphology of the mesostructures. In addition to silica which forms the majority in the literature on mesoporous thin films, $\mathrm{TiO}_{2},{ }^{20-37} \mathrm{ZrO}_{2},{ }^{29,32,38-47} \mathrm{CeO}_{2},{ }^{41,47-49} \mathrm{HfO}_{2},{ }^{50}$ $\mathrm{SnO}_{2},{ }^{51,52} \mathrm{Ta}_{2} \mathrm{O}_{5},{ }^{53}$ mixed metal oxides $\mathrm{ZrO}_{2}-\mathrm{CeO}_{2},{ }^{41}$ and binary metal oxides $\mathrm{NiTiO}_{3}{ }^{54} \mathrm{SrTiO}_{3},{ }^{55} \mathrm{MgTa}_{2} \mathrm{O}_{6},{ }^{55}$ and $\mathrm{Co}_{\mathrm{x}} \mathrm{Ti}_{1-\mathrm{x}} \mathrm{O}_{2-\mathrm{x}}{ }^{55}$ have been processed into mesoporous thin films. Mesoporous silicate with zeolitic wall also has been reported. ${ }^{56}$

The main reason for the endeavor to synthesize non-silica mesoporous materials in general is to take advantage of the physical properties of them. For example, $\mathrm{TiO}_{2}$ is wellknown for it photoactivity and $\mathrm{ZrO}_{2}$ is widely used as catalytic supports. Therefore, it would be interesting to see the combined effect of the physical properties of the wall materials and the properties arising from the mesoporosity. Similarly, semiconductors $\left(\mathrm{TiO}_{2}\right.$ and $\left.\mathrm{SnO}_{2}\right)$ and magnetic materials $\left(\mathrm{Co}_{\mathrm{x}} \mathrm{Ti}_{1-\mathrm{x}} \mathrm{O}_{2-\mathrm{x}}\right)$ that have mesoporous structures would be interesting research subjects.

The different chemistry of metal ions from that of silicon makes the synthesis of non-silica mesoporous materials much different in nature from that of silica, and, in general, much more difficult. The classical mechanism of the formation of mesoporous materials in which the surfactant molecules form ordered micellar structures with inorganic species associated with the hydrophilic portions of the micelle requires a subtle balance between two concurrent processes. One is the association between surfactant and the inorganic species into the mesostructures and the other is the hydrolysis and condensation reactions of the inorganic species into walls. In case of silica, the reaction rates of hydrolysis and condensation of silica species are rather slow, matching with the kinetics of the formation of mesostructures. On the contrary, such reactions are much faster for most of the other metal ions, which means that the inorganic species do not have enough time to associate with the surfactant micelles and form mesoscopic orderings. One 
may attempt to slow the hydrolysis and condensation reactions of metal ions, typically by using ligands such as glycolate, $\beta$-diketones, triethanolamine, and peroxide, but the dynamic nature of the whole process makes it extremely hard to balance the two types of kinetics.

Fortunately, however, the formation mechanisms of thin films are somewhat different and the problems of the fast hydrolysis and condensation reactions of metal ions may be alleviated. The most widely used formation process of mesoporous thin films is the evaporation-induced self-assembly (EISA) mechanism, first proposed by Brinker and coworkers. ${ }^{57}$ They formed mesoporous silica thin films by dipcoating a precursor solution composed of a silica precursor and surfactant $(\mathrm{CTAB})$ in an ethanol-water mixed solvent onto glass substrates. Unlike the powder synthesis, the concentration of the solution in this process is much lower, lower than the critical micelle concentration (CMC). While pulling the substrate upward, the solution coats the surface. As the solvent evaporates, the solution on the substrate becomes concentrated, crossing CMC to induce self-assembly of the surfactant and the silica species to form mesoscopic ordering. This process occurs almost spontaneously, within a few minutes at most. In case of silica synthesis, the silica species in the as-cast films can still undergo hydrolysis/condensation reactions to form rigid pore walls.

On the contrary, in case of other metal ions, the precursor solutions are often strongly acidic, enough to suppress the hydrolysis and condensation reactions of the metal ion species, so that the film materials form liquid crystal-like states. $^{58}$ The acidity of the solution is the result of using metal chlorides as the metal sources; addition of acid is necessary when metal alkoxides are used. The structure of the liquid crystal-like state can be tuned by changing temperature. So the aging at a designated temperature for a few days is required to attain ordered mesostructured films. Based on our unpublished results of synthesizing mesoporous titania thin films using ethanol solutions of $\mathrm{TiCl}_{4}$ and F127, the mesostructure could be tuned to cubic or hexagonal by aging at $18{ }^{\circ} \mathrm{C}$ or $35^{\circ} \mathrm{C}$, respectively. It was also possible to change the cubic structure obtained from aging at $18{ }^{\circ} \mathrm{C}$ to hexagonal by subsequent aging at $35{ }^{\circ} \mathrm{C}$. Moreover, the materials in the as-cast film could be completely dissolved into ethanol, demonstrating the liquid crystallike nature of the film material. However, since the acid, $\mathrm{HCl}$, also evaporates during aging, partial condensation may occur, and the problem of balancing the hydrolysis/condensation rates with that of self-assembly ensues again. In general, there are at least two different reactions, hydrolysis/ condensation of the inorganic precursor and microphase segregation to form the mesostructure, occurring simultaneously during the formation of mesoporous thin films, which makes the control of the pore morphology difficult. In this regard, we have developed a method in which the two reactions are separated by using pre-formed titania nanoparticles. Therefore, the titania precursor remains inactive while the mesostructure is formed allowing the system controllable by thermodynamics only. The mesostructure could be controlled by aging the as-prepared films under controlled environments including humidity and temperature. ${ }^{20,35,37}$ The liquid crystal mechanism enables one to use spin-casting instead of dip-coating used in ESIA process. Spin-casting is advantageous in that it can produce more even surfaces and the film thickness can be more easily controlled.

In addition to the aging temperature, the humidity level plays a crucial role in the mesostructure formation of the film materials. Over the past a few years it became clear that the humidity level during the processing was very important, and recently, papers describing mesoporous thin films have started to indicate the humidity levels in the experimental sections. Ozin and co-workers have reported that a high humidity level (ca. 60\%) during aging favors a cubic structure while lower humidity level (40\%) favors the hexagonal structure. However, we have found that the importance of humidity level is not restricted to the aging stage only. ${ }^{20}$ Figure 2 show the X-ray diffraction patterns of two as-cast films prepared in the same way except that the environmental humidity levels during spin casting are different. The film from a high humidity level formed a highly ordered mesostructure while the one from a low humidity a less ordered one. Even the unit cell sizes are different, as can be seen from the different peak positions. Our explanation is based on the mobility of the components in the as-cast films. If the film is prepared with moisture, the water molecules remaining in the film material function as a lubricant so that the materials can move and reorient to form the thermodynamically most stable state, which is the mesostructure. If there is not enough water lubricant, such mobility is not possible and the stable mesostructure is not attainable. Since water evaporates during aging, the initial water content is decreased with time. Therefore, the initial water content,

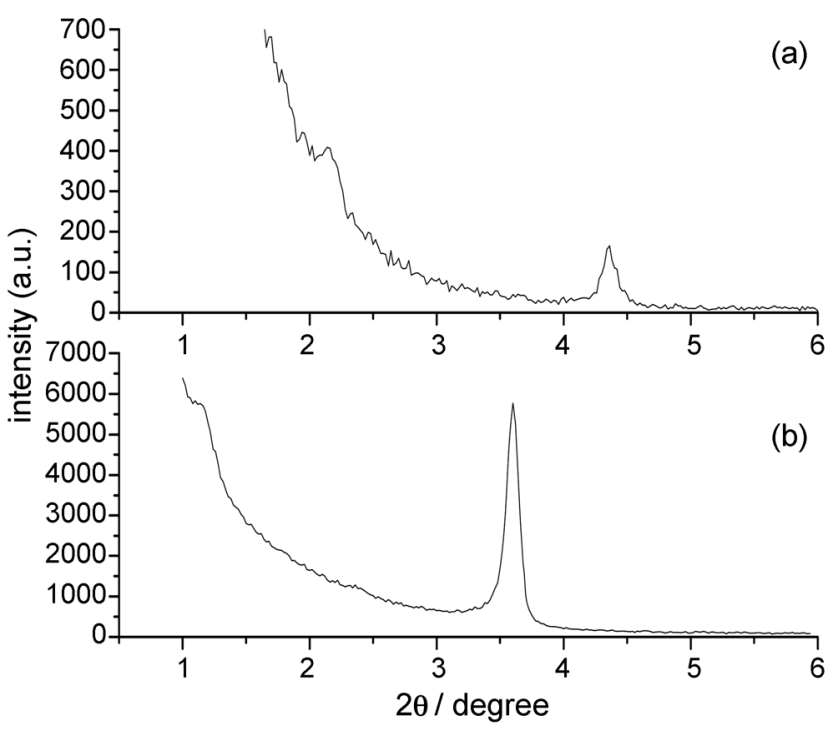

Figure 2. X-ray diffraction patterns of as-cast films of mesostructure titania under different humidity levels during spincasting: (a) $30 \%$ and (b) $60 \%$. Reproduced with permission from ref. 20 . 
concentration

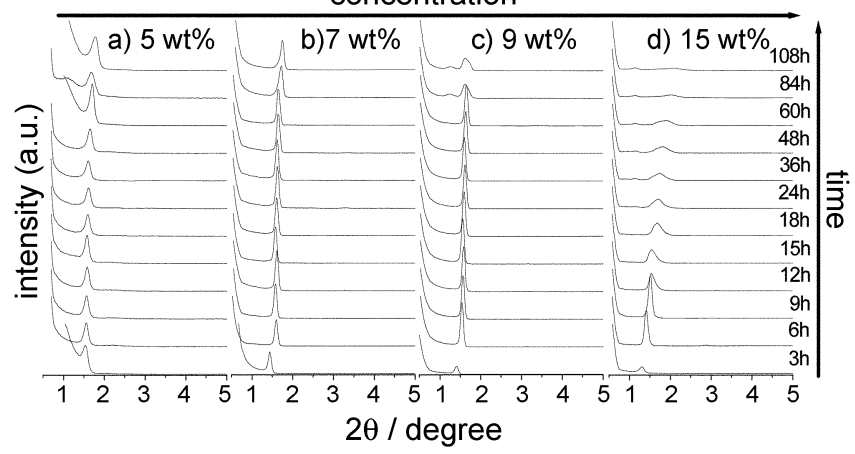

Figure 3. Series of X-ray diffraction patterns of as-cast mesostructured thin films with time. The films were prepared with varied amounts of surfactants. Reproduced with permission from ref. 20.

which is controlled by the environmental humidity level during spin-casting is an important factor that determines the final mesostructure. This explanation is supported from the series of XRD patterns in Figure 3 taken as a function of aging time. In this figure, it is clear that the mesostructure changes as a function of aging time. In support of this explanation, Crepaldi et al. reported that the humidity level determines the water content in the film material and that a certain amount of water in the film is necessary to make the film materials flexible. ${ }^{58}$

Another important issue in forming non-silica mesoporous materials is the crystallization of the wall materials. ${ }^{3}$ Silica normally does not undergo crystallization at high temperatures, which is a beneficial feature for silica in forming mesoporous structures because crystallization often accompanies the collapse of the porous structures. On the other hand, non-silica materials undergo crystallization even at temperatures as low as $400{ }^{\circ} \mathrm{C}$. Therefore, mesostructures of non-silica materials generally show thermal instability, limiting the calcination temperature to below $400{ }^{\circ} \mathrm{C}$. However, some of the desired features of mesoporous materials require high degree of crystallinity of the wall materials. For example, the crystallinity of titania strongly influences its photoactivity. Several papers report mesoporous thin films of non-silica wall materials with some degree of crystallinity. Based on in-situ, time-resolved small- and wide-angle X-ray scattering investigations, simultaneously performed during thermal treatment of titania films in various conditions, Sanchez and co-workers have shown that the temperature program applied during treatment is critical because it affected the whole film morphology at the meso- and microscales through the network shrinkage and crystallization, respectively. Their studies also confirmed that the mesoporous structure was greatly affected by the crystallization of the $\mathrm{TiO}_{2}$ network. ${ }^{27,29}$ Ozin's group has taken a different approach of changing the solvent of the precursor solution. The solvent of choice for most of the processes in the literature is ethanol for it is a good solvent for the inorganic precursors and surfactants. However, ethanol has a drawback of having narrow range of synthetic conditions, such as temperature and humidity level. The increased CMC in an ethanol solution requires rather large amount of surfactant, typically P123 making the P123/Ti ratio high, which might be the reason for the thermal instability of the mesoporous titania that forms from ethanol-containing precursor solution. Because of the increased hydrophobicity, butanol has the effect of reducing the CMC of the P123-Ti system, making thicker walls with increased thermal stability. ${ }^{26}$ They showed that the films could be calcined at $400{ }^{\circ} \mathrm{C}$ without loosing the mesoporosity; the high temperature allowed the crystallization of titania into anatase. Butanol appears to have additional advantages over ethanol for the production of thick films; the details are discussed in Ozin's paper. Unfortunately, their films have 2D hexagonal structures with limited applicability. Whether this modification can be applied to the synthesis of more useful cubic structures or even hexagonal structures with vertical channels is yet to be explored.

Another interesting approach has been made by Stucky's group. ${ }^{25}$ They first formed a mesoporous titania thin film into a cubic structure before the removal of surfactant. This film was partially calcined at a low temperature of $300{ }^{\circ} \mathrm{C}$, the pores so formed were filled by carbon using furfuryl alcohol. The carbon inside the pore fortified the mesostructure, which allowed heat treatments up to $750{ }^{\circ} \mathrm{C}$, at which temperature titania wall underwent crystallization into anatase without losing the mesoporosity. At the same time, part of the support carbon was removed. This carbon supported titania mesoporous film had both mesoporosity and wall crystallinity, and showed high activity for water photoloysis.

The addition of cerium ions to mesoporous titania thin films improves the mesoscopic order of the final calcined material by increasing the domain size. ${ }^{36}$ It is known that lanthanide ions are not as reactive as the titania precursor species, and the ability of the lanthanides to interfere with the condensation and crystallization of the titanium oxide matrix has been used to explain an increase in thermal stability in wormlike mesoporous materials as well as an inhibition of the growth of titania nanocrystals. This interruption of the network is also likely to be the reason for an increase in mesostructural order. However, the addition of $\mathrm{Ce}$ (III) decreased the photoconductivity more than by an order even with a few at $\%$ of $\mathrm{Ce}$.

\section{Thin Films with Accessible Pores from Surfaces}

One of the most intriguing tasks in the synthesis of mesoporous thin films is the alignment of the pores. Many potential applications of mesoporous thin films rely on the ability to form films with accessible pores from the surface. The most prevailing 2D hexagonal mesoporous thin films have their pores parallel to the surface because the interfaces (substrate/film and film/air) prefer contact with either the hydrophilic or hydrophobic part of the surfactants depending on the nature of the substrate. This is the very reason why many groups have attempted synthesize cubic mesoporous 


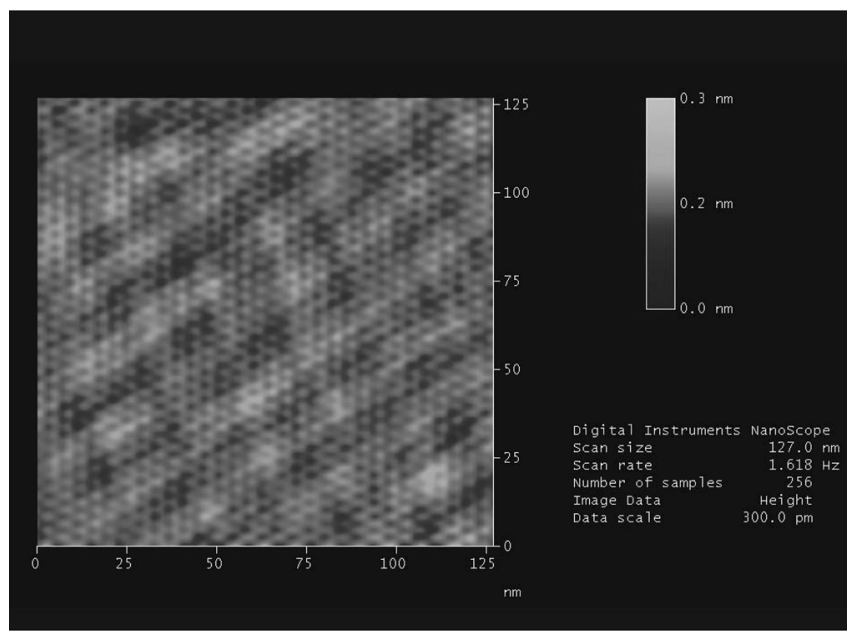

Figure 4. Atomic force microscopic image of a mesoporous titania thin film synthesized by the nanoparticle route. Reproduced with permission from ref. 20.

films, which, by the nature of the cubic symmetry, there must be pore openings from the surfaces regardless the orientation. ${ }^{23,24,27,29,35,37,40,59-84}$ Several different strategies have been employed to form cubic structured mesoporous thin films. The most popular approach is to find the optimal composition of the precursor solution by varying the mixing ratios of surfactant and inorganic precursor including surfactant/metal ratio, ${ }^{20,35,60,77,79,80,82-85}$ the molar ratio between metals when mixed metal oxide were synthesized, the nature and amount of added hydrocarbon, ${ }^{76}$ and the amount of added water. ${ }^{37,61,63,65,66,68-73}$ From a study on the synthesis of mesoporous silica thin films, Park et al. reported that $\mathrm{EO}_{77} \mathrm{PO}_{29} \mathrm{EO}_{77}$ (F68) among several Pluronic type triblock copolymers they used directed to a cubic structure. ${ }^{81}$ Other groups have varied the aging temperature that formed cubic structures.$^{67}$ Lee's group reported that the spin speed during the film casting by spin-coating could determine the mesostructures. ${ }^{23,62}$ Our nanoparticle route mentioned above also could be adapted by controlling the composition and annealing temperature to form a cubic structure. The titania thin films by this method have unusually smooth surface. The AFM image in Figure 4 on the surface over a $100 \times 100$ $\mathrm{nm}^{2}$ area shows that the surface is atomically flat within 0.3 $\mathrm{nm}$.

Very recently, remarkable advances have been made to synthesize 2D hexagonal mesostructured thin films with the pores orthogonal to the film surfaces. By applying a strong magnetic field of $12 \mathrm{~T}$ during the film casting, Kuroda's group has been able to form films with orthogonal pores. The interaction energy between the strong magnetic field and the anisotropic diamagnetic susceptibility of the lyotropic liquid crystals exceeds the thermal fluctuation when the field strength is high. However, even such a strong field appears not enough to completely align the channels and their films show distribution of the pore directions by $\pm 15^{\circ} .86$

Probably, much more reliable method is the control of the interfacial energies of substrate/film and air/film. Theoretical studies suggested that block copolymers confined by two identical walls may be able to form perpendicular channels. The synthesis of platelets of SBA-15 with pores perpendicular to the platelet surfaces reported by Chen et al. demonstrated such possibility. Although the details may take lengthy description, their idea was very simple: They synthesized SBA-15 by using sodium silicate and P123 surfactant in the presence of hexadecyltrimethylammonium bromide $\left(\mathrm{C}_{16} \mathrm{TMAB}\right)$ and sodium dodecylsulfate (SDS). The cationic and anionic surfactants form bilayers. Between the layers the silica/P123 precursor intercalates and forms SBA15. P123 molecules interact strongly with the surfaces of the bilayers. ${ }^{87}$ Although their method may not be applicable to synthesis of thin films, their strategy may find a way to the fabrication of mesoporous thin films with vertical channels.

Mesoporous thin films with vertical channels were realized by two groups in 2005. While the details are different in these two papers, the underlying principles are very similar to those of the synthesis of platelets with vertical channels. The approach by Freer $e t$ al. was to use the self-assembly of Poly(styrene-block-ethylene oxide) (PS-b-PEO) block copolymer and silsesquioxane on aminopropyltriethoxysilicate (APTES) or Au coated silicon. ${ }^{88}$ By varying the molar ratio of PS-b-PEO and silsesquioxane, they found that 50/50 and 30/70 (wt/wt) compositions produced cylindrical and spherical pore morphologies, respectively. Furthermore, they found that the cylindrical pores are vertical when formed on APTES or Au coated silicon substrate. However, at the top of the film, there are few parallel channels. This problem could be circumvented by aging the film under a vapor of a $50 / 50(\mathrm{v} / \mathrm{v})$ chloroform/octane liquid mixture, resulting in almost vertical channels over a large area. The approach by Koganti and Rankin appears to be much simpler because they synthesized SBA-15 by using more readily available P123 block copolymer as a template. ${ }^{89}$ They first prepared glass substrates whose surfaces were modified with $\mathrm{P} 123$ or a random copolymer of PEO and PPO. Because of the composition of the surface modifier is the same as that of the template molecules, the surface does not have any preference for either the PEO or PPO part of the surfactant, viz. the surface is neutral to either type of blocks of the template molecule. After casting the precursor solution for SBA-15 onto a modified substrate, they immediately covered the film with another modified glass from the top so that the film material experienced symmetric interfacial energies on both sides. However, our own experience of this technique tells that the supposed mechanism works only for a fraction of the films, and the majority of the pores are still parallel to the substrate surface.

\section{Mesoporous Thin Films as Nanotemplates}

Mesoporous materials already have a long history of being used as templates for the synthesis of nanomaterials. In case of powders, the most widely used and probably the only possible method is impregnating reagents into the pores and 
converting them into nanoparticles or nanorods. On the contrary, in case of using thin films as templates, the simple impregnation method may have a problem of restricted dimensionality of the template because the thin films are usually formed on substrates. Hexagonal structures may be even harder to be used as templates because of the lack of accessible pore openings. On the other hand, when formed as non-hexagonal structures on conductive substrates, electrochemical deposition technique may be applied. Some times, various gas-phase deposition techniques can be used. The electrochemical deposition into the pores of mesoporous thin film templates appears to have many beneficial features. For example, this method may yield nanomaterials in very high number densities. Since the pore dimension and pore-to-pore distance are typically 10 and $15 \mathrm{~nm}$, respectively, or smaller, the number density of the nanoparticles or nanorods to be formed may exceed $10^{12} \mathrm{~cm}^{-2}$. Assuming such a structure is fabricated with magnetic materials and each such nanoparticle or nanorod forms single domain, it may be possible to form 6 terabit magnetic memories. By controlling the amount of current passed, one may be able to control the length of the nanorods. Examples in which mesoporous thin films have been used as templates are described below according to the method used.

Impregnation of reagents. Nanoparticles of noble metals and magnetic metals have been synthesized in the pores of mesoporous thin films of $\mathrm{SiO}_{2}$ and $\mathrm{TiO}_{2}$. Ag nanoparticles were generated by the photocatalytic reduction reaction of $\mathrm{TiO}_{2}$ after impregnating the pores with $\mathrm{AgCl} .{ }^{90} \mathrm{Pt}$ nanoparticle inside $\mathrm{TiO}_{2}$ were synthesized by impregnating with $\mathrm{PtCl}_{4}{ }^{2-}$ ions and reduction by hydrogen at high temperatures. ${ }^{24}$ Through a series of papers, Gu et al. have reported incorporation of nanoparticles of $\mathrm{Fe}_{2} \mathrm{O}_{3},{ }^{91} \mathrm{Pd}^{91}$ and $\mathrm{Au}^{92,93}$ into $\mathrm{SiO}_{2}$ films. They modified the inner surface to endow hydrophobicity which enhanced the amount of metal precursor loading. Gas-phase impregnation has been tried to synthesize nanowires of magnetic metals such as $\mathrm{Co}$ and $\mathrm{Fe}$. Cobalt octacarbonyl and iron dodecacarbonyl precursors were introduced into the high-pressure reaction cell in a tube furnace. Reactions at $300-500{ }^{\circ} \mathrm{C}$ produced ultra-thin $\mathrm{Co}$ and $\mathrm{Fe}_{3} \mathrm{O}_{4}$ nanowires with diameter of 4-5 nm and density up to $10^{12} \mathrm{~cm}^{2}$ embedded into mesoporous silica matrices. The nanowires were arranged in the plane of the Si substrate after the removal of the templates. Another paper on the synthesis of magnetic nanowires inside the pores reported that the nanowire arrays show magnetization reversal that was strongly temperature dependent. ${ }^{94}$ Semiconductor $\mathrm{CdS}^{95}$ and $\mathrm{PbS}^{96}$ nanoparticles and diluted magnetic semiconductor $\mathrm{Cd}_{1-\mathrm{x}} \mathrm{Mn}_{\mathrm{x}} \mathrm{S}$ nanoparticles inside $\mathrm{SiO}_{2}{ }^{97}$ have been produced by impregnating metal ions and subsequent treatments with $\mathrm{H}_{2} \mathrm{~S}$ vapor. A similar work was reported by Stucky's group who reported the synthesis of CdS or CdSe containing mesoporous $\mathrm{TiO}_{2}$ that exhibited enhanced visible light sensitivity. ${ }^{98}$ Instead of impregnating $\mathrm{Cd}^{2+}$ ions into the pore, they achieve $\mathrm{Cd}^{2+}$ impregnation by mixing $\mathrm{CdCl}_{2}$ into the precursor solution of titania and surfactant. Supercritical fluid was also used to impregnate semiconductor crystals inside the mesoporous thin films. ${ }^{99-101}$ Finally, sonochemical treatment of mesoporous $\mathrm{TiO}_{2}$ in a $\mathrm{AuCl}_{4}^{3-}$ solution followed by a reduction reaction was reported. ${ }^{102}$ The sonochemistry produced highly dispersed Au nanoparticles.

Chemical vapor deposition. Although rare, probably because of the anticipated difficulty in filling the pores, vapor deposition technique was also employed for the synthesis of nanomaterials inside the nanopores of mesoporous films. Nanoparticles of $\mathrm{CdS}$ and $\mathrm{CuInS}_{2}$ were formed inside the pores of mesoporous $\mathrm{TiO}_{2}$ by low pressure MOCVD. ${ }^{103} \mathrm{Si}$ nanocrystals were incorporated into the hexagonal $\mathrm{SiO}_{2}$ by $\mathrm{CVD}$ of disilane molecules. ${ }^{104}$

In addition, an interesting process was reported for the synthesis of $\mathrm{TiO}_{2}$ nanofibers that is grown on top of the mesoporous silica film. In this study, $\mathrm{TiO}_{2}$ nanofibers have been made by impregnating a mesoporous silica film with $\mathrm{TiCl}_{4}$ followed by hydrolysis in air. The $\mathrm{TiO}_{2}$ nanofiber morphology can be varied by controlling the pore size and pore volume of the mesoporous silica film. $\mathrm{TiO}_{2}$ nanofiber diameters were in the range of 30-200 $\mathrm{nm}$. The as-synthesized nanofibers are amorphous but crystallize to anatase at $250{ }^{\circ} \mathrm{C}$ without a change in morphology. ${ }^{105}$

Electrochemical deposition. As mentioned above, the thin film morphology may be used for electrochemical deposition of nanomaterials into the pores of mesoporous films. However, in order to apply this technique, there must be open pores accessible from the film surface, which requires, at present the cubic structure. Electrochemical deposition has the advantages in that it allows very high number densities of the nanomaterials to be formed and has a means to control the extent of growth. Many techniques used in electrochemical deposition to form thin films may be readily adopted. In the literature, nanostructured $\mathrm{Au}$ in the pores of $\mathrm{TiO}_{2},{ }^{106}$ nanowires of magnetic $\mathrm{Co}$ and $\mathrm{Fe}$ into $\mathrm{SiO}_{2}$ are reported. ${ }^{64}$ In the last case, $\mathrm{Fe}$ nanowires undergo oxidation to result in $\mathrm{Fe}_{2} \mathrm{O}_{3}$ nanowire arrays. Small amount of Fe was deposited into the pores of the SBA-16 thin film and was used for the growth carbon nanotube arrays inside the pores of SBA-16 film by catalytic decomposition of acetylene at $700{ }^{\circ} \mathrm{C} \cdot{ }^{75,107} \mathrm{CdS}$ nanowires of high density were grown by periodic pulse electrodeposition into $\mathrm{SiO}_{2}{ }^{108}$

Our group has also worked on synthesizing nanostructured materials by using electrochemical deposition method. We have used cubic mesoporous silica and titania thin films as templates. The mesoporous films were formed on conductive substrates such as FTO, ITO, and Pt or Au deposited Si wafer. Some of the preliminary data will be described briefly.

Nanostructured polyaniline inside mesoporous titania (PANI@m-TiO $)_{2}$ ): Electrochemical deposition of polyaniline into the pores of a mesoporous titania thin film (pore size $10 \mathrm{~nm}$ ) from an aniline solution with $\mathrm{HCl}$ electrolyte resulted in rather unusual structure shown in Figure 5. This AFM image shows that the polyaniline has grown out most of the pores and form nanorods. The nanorods are $10 \mathrm{~nm}$ wide and about $100 \mathrm{~nm}$ high above the surface of the titania film. This rather unusual structure and related materials may 


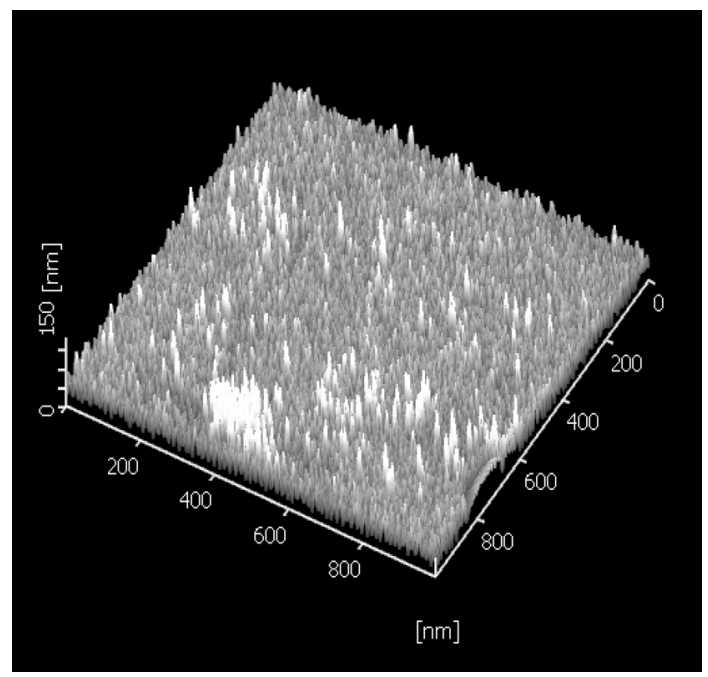

Figure 5. AFM image of nanostructured PANI grown into mesoporous titania thin film.

be able to find applications such as solar cells. ${ }^{109}$

Nanostructured platinum with high surface area: ${ }^{10}$ Electrochemical deposition of $\mathrm{Pt}$ into a cubic structured mesoporous silica film on an electrode (Pt-coated Si wafer) followed by leaching out the silica template with a HF solution resulted in nanostructured $\mathrm{Pt}$ thin film. The film is composed of vertically standing Pt nanorods of $9 \mathrm{~nm}$ in diameter. Interestingly, each Pt nanowire was found to be single crystalline, probably because of the confinement effect of the small pores.

Nanostructure cobalt with interesting magnetism: ${ }^{111}$ Electrochemical deposition of Co into the pores of mesoporous silica thin films produced arrays of Co nanorods of $10 \mathrm{~nm}$ in diameter. Luo et al also have reported synthesis of nanostructured $\mathrm{Co}$ by using silica templates with various pore structures. ${ }^{64}$ These nanostructured Co thin films show enhanced coercivity by an order from those of Co thin films without a nanostructure.

\section{Conclusions and Outlook}

In this short review, we have surveyed mesoporous thin films with emphases on those with accessible pores from the film surfaces. While last year has witnessed remarkable advances with the development of synthetic methods to form hexagonal mesoporous films with vertical pores, still the pore accessibility requirement still poses a heavy limitation that the structure be cubic. Therefore, much effort has been paid to establish synthetic conditions for cubic structures. Most of the nanomaterials derived from mesoporous thin films also are based on the cubic structure, although our group has demonstrated that templates with hexagonal structure also can function as hosts when employing electrochemical deposition technique. Although not covered in this paper, the nanocomposites derived from the mesoporous thin films show many interesting properties, some of which may lead to the realization of nanodevices in the future.
Acknowledgements. This work was supported by the Korea Research Foundation Grant funded by the Korean Government (MOEHRD) (KRF-2005-005-J11903). This work is also supported by the Center for Nanotubes and Nanostructured Composites.

\section{References}

1. Kresge, C. T.; Leonowicz, M. E.; Roth, W. J.; Vartuli, J. C.; Beck, J. S. Nature 1992, 359, 710.

2. Beck, J. S.; Vartuli, J. C.; Roth, W. J.; Leonowicz, M. E.; Kresge, C. T.; Schmitt, K. D.; Chu, C. T.-W.; Olson, D. H.; Sheppard, E. W.; McCullen, S. B.; Higgins, J. B.; Schenkler, J. L. J. Am. Chem. Soc. 1992, 114, 10834.

3. Kleitz, F.; Kim, T.-W.; Ryoo, R. Bull. Korean Chem. Soc. 2005 , $26,1653$.

4. Soler-Illia, G.; Crepaldi, E. L.; Grosso, D.; Sanchez, C. Curr. Opin. Colloid Interface Sci. 2003, 8, 109

5. Scott, B. J.; Wirnsberger, G.; Stucky, G. D. Chem. Mater. 2001, 13, 3140.

6. Schuth, F. Chem. Mater. 2001, 13, 3184.

7. Ciesla, U.; Schuth, F. Micropor. Mesopor. Mater. 1999, 27, 131.

8. Sayari, A. Chem. Mater. 1996, 8, 1840.

9. Yang, H.; Kuperman, A.; Coombs, N.; MamicheAfara, S.; Ozin, G. A. Nature 1996, 379, 703.

10. Ogawa, M. Colloid Polym. Sci. 2003, 281, 665.

11. Topoglidis, E.; Discher, B. M.; Moser, C. C.; Dutton, P. L.; Durrant, J. R. Chembiochem 2003, 4, 1332.

12. Nicole, L.; Boissiere, C.; Grosso, D.; Quach, A.; Sanchez, C. J. Mater. Chem. 2005, 15, 3598.

13. Guliants, V. V.; Carreon, M. A.; Lin, Y. S. J. Membr. Sci. 2004, 235, 53.

14. Pevzner, S.; Regev, O.; Yerushalmi-Rozen, R. Curr. Opin. Colloid Interface Sci. 1999, 4, 420.

15. Hunks, W. J.; Ozin, G. A. J. Mater. Chem. 2005, 15, 3716

16. Bartl, M. H.; Boettcher, S. W.; Frindell, K. L.; Stucky, G. D. Acc. Chem. Res. 2005, 38, 263.

17. Shi, J. L.; Hua, Z. L.; Zhang, L. X. J. Mater. Chem. 2004, 14, 795.

18. Sanchez, C.; Lebeau, B.; Chaput, F.; Boilot, J. P. Adv. Mater. 2003, $15,1969$.

19. Sanchez, C.; Boissiere, C.; Coupe, A.; Goettmann, F.; Grosso, D.; Julian, B.; Llusar, M.; Nicole, L. In Nanoporous Materials IV 2005; Vol. 156, p 19.

20. Lee, U. H.; Lee, H.; Wen, S.; Mho, S.-i.; Kwon, Y.-U. Micropor. Mesopor. Mater. 2006, 88, 48.

21. Wark, M.; Tschirch, J.; Bartels, O.; Bahnemann, D.; Rathousky, J. Micropor. Mesopor. Mater. 2005, 84, 247.

22. Liu, K. S.; Zhang, M. L.; Shi, K. Y.; Fu, H. G. Mater. Lett. 2005, 59, 3308.

23. Pan, J. H.; Lee, W. I. New J. Chem. 2005, 29, 841.

24. Wang, X. C.; Yu, J. C.; Yip, H. Y.; Wu, L.; Wong, P. K.; Lai, S. Y. Chem.-Eur. J. 2005, 11, 2997.

25. Tang, J.; Wu, Y. Y.; McFarland, E. W.; Stucky, G. D. Chem Commun. 2004, 1670.

26. Choi, S. Y.; Mamak, M.; Coombs, N.; Chopra, N.; Ozin, G. A. Adv. Func. Mater. 2004, 14, 335.

27. Grosso, D.; Soler-Illia, G.; Crepaldi, E. L.; Cagnol, F.; Sinturel, C.; Bourgeois, A.; Brunet-Bruneau, A.; Amenitsch, H.; Albouy, P. A.; Sanchez, C. Chem. Mater. 2003, 15, 4562.

28. Paik, J. A.; Fan, S. K.; Chang, H.; Kim, C. J.; Wu, M. C.; Dunn, B. J. Electroceram. 2004, 13, 423.

29. Crepaldi, E. L.; Soler-Illia, G.; Grosso, D.; Sanchez, M. New J. Chem. 2003, 27, 9.

30. Varghese, O. K.; Grimes, C. A. J. Nanosci. Nanotech. 2003, 3, 277.

31. Yun, H. S.; Miyazawa, K.; Honma, I.; Zhou, H. S.; Kuwabara, M. Mater. Sci. Eng. C 2003, 23, 487. 
32. Crepaldi, E. L.; Soler-Illia, G.; Grosso, D.; Albouy, P. A.; Amenitsch, H.; Sanchez, C. In Nanoporous Materials III 2002; Vol. 141, p 235.

33. Yu, J. C.; Yu, J. G.; Zhao, J. C. Appl. Catal. B-Environ. 2002, 36, 31.

34. Yun, H. S.; Miyazawa, K.; Zhou, H. S.; Homma, I.; Kuwabara, M. J. Ceram. Soc. Jpn. 2002, 110, 373.

35. Hwang, Y. K.; Lee, K. C.; Kwon, Y. U. Chem. Commun. 2001, 1738.

36. Frindell, K. L.; Tang, J.; Harreld, J. H.; Stucky, G. D. Chem. Mater. 2004, 16, 3524.

37. Lee, U. H.; Hwang, Y. K.; Kwon, Y. U. In Nanotechnology in Mesostructured Materials 2003; Vol. 146, p 77.

38. Smirnova, N.; Eremenko, A.; Gayvoronskij, V.; Petrik, I.; Gnatyuk, Y.; Krylova, G.; Korchev, A.; Chuiko, A. J. Sol-Gel Sci. Tech. 2004, 32, 357.

39. Angelome, P. C.; Soler-Illia, G. Chem. Mater. 2005, 17, 322.

40. Angelome, P. C.; Aldabe-Bilmes, S.; Calvo, M. E.; Crepaldi, E. L.; Grosso, D.; Sanchez, C.; Soler-Illia, G. New J. Chem. 2005, 29, 59 .

41. Brezesinski, T.; Antonietti, M.; Groenewolt, M.; Pinna, N.; Smarsly, B. New J. Chem. 2005, 29, 237.

42. Grosso, D.; Crepaldi, E. L.; Illia, G. J. D.; Cagnol, F.; Baccile, N.; Babonneau, F.; Albouy, P. A.; Amenitsch, H.; Sanchez, C. In Nanotechnology In Mesostructured Materials 2003; Vol. 146, p 281.

43. Bergeron, B. V.; Meyer, G. J. J. Phys. Chem. B 2003, 107, 245.

44. Yang, D.; Qi, L. M.; Ma, J. M. J. Mater. Chem. 2003, 13, 1119.

45. Galoppini, E.; Guo, W. Z.; Zhang, W.; Hoertz, P. G.; Qu, P.; Meyer, G. J. J. Am. Chem. Soc. 2002, 124, 7801.

46. Zhang, Y. W.; Yang, Y.; Tian, S. J.; Liao, C. S.; Yan, C. H. J. Mater. Chem. 2002, 12, 219.

47. Gao, X. T.; Wachs, I. E. J. Phys. Chem. B 2000, 104, 1261.

48. Moller, M. T.; Asaftei, S.; Corr, D.; Ryan, M.; Walder, L. Adv. Mater. 2004, 16, 1558.

49. Lundberg, M.; Skarman, B.; Cesar, F.; Wallenberg, L. R. Micropor. Mesopor. Mater. 2002, 54, 97.

50. Brezesinski, T.; Smarsly, B.; Iimura, K.; Grosso, D.; Boissiere, C.; Amenitsch, H.; Antonietti, M.; Sanchez, C. Small 2005, 1, 889.

51. Hyodo, T.; Abe, S.; Shimizu, Y.; Egashira, M. Sensors Actuat. BChem. 2003, 93, 590

52. Hyodo, T.; Nishida, N.; Shimizu, Y.; Egashira, M. Sensors Actuat. B-Chem. 2002, 83, 209.

53. Sreethawong, T.; Ngamsinlapasathian, S.; Suzuki, Y.; Yoshikawa, S. J. Mol. Catal. A-Chem. 2005, 235, 1.

54. de Zarate, D. O.; Boissiere, C.; Grosso, D.; Albouy, P. A.; Amenitsch, H.; Amoros, P.; Sanchez, C. New J. Chem. 2005, 29, 141.

55. Grosso, D.; Boissiere, C.; Smarsly, B.; Brezesinski, T.; Pinna, N.; Albouy, P. A.; Amenitsch, H.; Antonietti, M.; Sanchez, C. Nature Mater. 2004, 3, 787.

56. Petkov, N.; Holzl, M.; Metzger, T. H.; Mintova, S.; Bein, T. J. Phys. Chem. B 2005, 109, 4485.

57. Brinker, C. J.; Lu, Y.; Sellinger, A.; Fan, H. Y. Adv. Mater. 1999, 11,579 .

58. Crepaldi, E. L.; Soler-Illia, G.; Grosso, D.; Cagnol, F.; Ribot, F.; Sanchez, C. J. Am. Chem. Soc. 2003, 125, 9770.

59. Yu, J. C.; Wang, X. C.; Fu, X. Z. Chem. Mater. 2004, 16, 1523.

60. Alberius, P. C. A.; Frindell, K. L.; Hayward, R. C.; Kramer, E. J.; Stucky, G. D.; Chmelka, B. F. Chem. Mater. 2002, 14, 3284.

61. Matheron, M.; Bourgeois, A.; Brunet-Bruneau, A.; Albouy, P. A.; Biteau, J.; Gacoin, T.; Boilot, J. P. J. Mater. Chem. 2005, 15, 4741.

62. Pan, J. H.; Lee, W. I. Bull. Korean Chem. Soc. 2005, 26, 418.

63. Hwang, Y. K.; Patil, K. R.; Jhung, S. H.; Chang, J. S.; Ko, Y. J.; Park, S. E. Micropor. Mesopor. Mater. 2005, 78, 245.

64. Luo, H. M.; Wang, D. H.; He, J. B.; Lu, Y. F. J. Phys. Chem. B 2005, 109, 1919.

65. Jung, J. I.; Bae, J. Y.; Bae, B. S. J. Sol-Gel Sci. Tech. 2004, 31,
179.

66. Shimura, N.; Ogawa, M. Bull. Chem. Soc. Jpn. 2004, 77, 1599.

67. Hayward, R. C.; Alberius, P. C. A.; Kramer, E. J.; Chmelka, B. F. Langmuir 2004, 20, 5998.

68. Jung, J. I.; Bae, J. Y.; Bae, B. S. J. Mater. Chem. 2004, 14, 1988.

69. Soler-Illia, G.; Crepaldi, E. L.; Grosso, D.; Sanchez, C. J. Mater. Chem. 2004, 14, 1879.

70. Bae, J. Y.; Park, O. H.; Jung, J. I.; Ranjit, K. T.; Bae, B. S. Micropor. Mesopor. Mater. 2004, 67, 265.

71. Dunphy, D. R.; Singer, S.; Cook, A. W.; Smarsly, B.; Doshi, D. A.; Brinker, C. J. Langmuir 2003, 19, 10403.

72. Cagnol, F.; Grosso, D.; Soler-Illia, G.; Crepaldi, E. L.; Babonneau, F.; Amenitsch, H.; Sanchez, C. J. Mater. Chem. 2003, 13, 61.

73. Besson, S.; Gacoin, T.; Ricolleau, C.; Jacquiod, C.; Boilot, J. P. J. Mater. Chem. 2003, 13, 404.

74. Petkov, N.; Mintova, S.; Jean, B.; Metzger, T.; Bein, T. Mater. Sci. Eng. C 2003, 23, 827.

75. Petkov, N.; Mintova, S.; Karaghiosoff, K.; Bein, T. Mater. Sci. Eng. C 2003, 23, 145.

76. Ruggles, J. L.; Gilbert, E. P.; Holt, S. A.; Reynolds, P. A.; White, J. W. Langmuir 2003, 19, 793.

77. Shioya, Y.; Ikeue, K.; Ogawa, M.; Anpo, M. Appl. Catal. A.-Gen. 2003, 254, 251.

78. Yantasee, W.; Lin, Y. H.; Li, X. H.; Fryxell, G. E.; Zemanian, T. S.; Viswanathan, V. V. Analyst 2003, 128, 899.

79. Grosso, D.; Babonneau, F.; Albouy, P. A.; Amenitsch, H.; Balkenende, A. R.; Brunet-Bruneau, A.; Rivory, J. Chem. Mater. 2002, 14,931

80. Ikeue, K.; Nozaki, S.; Ogawa, M.; Anpo, M. Catal. Lett. 2002, 80, 111.

81. Park, G. S.; Ahn, C. W.; Kim, M. W. J. Am. Ceram. Soc. 2002, 85, 2542.

82. Faget, L.; Berman, A.; Regev, O. Thin Solid Films 2001, 386, 6.

83. Ogawa, M.; Ikeue, K.; Anpo, M. Chem. Mater. 2001, 13, 2900.

84. Ogawa, M.; Masukawa, N. Micropor. Mesopor. Mater. 2000, 38, 35.

85. Lu, Y. F.; Ganguli, R.; Drewien, C. A.; Anderson, M. T.; Brinker, C. J.; Gong, W. L.; Guo, Y. X.; Soyez, H.; Dunn, B.; Huang, M. H.; Zink, J. I. Nature 1997, 389, 364.

86. Yamauchi, Y.; Sawada, M.; Noma, T.; Ito, H.; Furumi, S.; Sakka, Y.; Kuroda, K. J. Mater. Chem. 2005, 15, 1137.

87. Chen, B. C.; Lin, H. P.; Chao, M. C.; Mou, C. Y.; Tang, C. Y. $A d v$. Mater. 2004, 16, 1657.

88. Freer, E. M.; Krupp, L. E.; Hinsberg, W. D.; Rice, P. M.; Hedrick, J. L.; Cha, J. N.; Miller, R. D.; Kim, H. C. Nano Lett. 2005, 5, 2014.

89. Koganti, V. R.; Rankin, S. E. J. Phys. Chem. B 2005, 109, 3279.

90. Andersson, M.; Birkedal, H.; Franklin, N. R.; Ostomel, T.; Boettcher, S.; Palmqvist, A. E. C.; Stucky, G. D. Chem. Mater. 2005, 17, 1409 .

91. Gu, J. L.; Shi, J. L.; Xiong, L. M.; Chen, H. R.; Ruan, M. L. Micropor. Mesopor. Mater. 2004, 74, 199.

92. Gu, J. L.; Shi, J. L.; Hua, Z.; Xiong, L. M.; Zhang, L. X.; Li, L. Chem. Lett. 2005, 34, 114.

93. Gu, J. L.; Shi, J. L.; Xiong, L. M.; Chen, H. R.; Li, L.; Ruan, M. L. Solid State Sci. 2004, 6, 747.

94. Kazakova, O.; Erts, D.; Crowley, T. A.; Kulkarni, J. S.; Holmes, J. D. J. Magn. Magn. Mater. 2005, 286, 171.

95. Patil, K. R.; Hwang, Y. K.; Kim, D. K.; Chang, J. S.; Park, S. E. Bull. Korean Chem. Soc. 2005, 26, 1025.

96. Buso, D.; Falcaro, P.; Costacurta, S.; Guglielmi, M.; Martucci, A.; Innocenzi, P.; Malfatti, L.; Bello, V.; Mattei, G.; Sada, C.; Amenitsch, H.; Gerdova, I.; Hache, A. Chem. Mater. 2005, 17, 4965.

97. Kouzema, A. V.; Froba, M.; Chen, L. M.; Klar, P. J.; Heimbrodt, W. Adv. Func. Mater. 2005, 15, 168.

98. Bartl, M. H.; Puls, S. P.; Tang, J.; Lichtenegger, H. C.; Stucky, G. D. Angew. Chem., Int. Ed. Engl. 2004, 43, 3037. 
99. Ziegler, K. J.; Polyakov, B.; Kulkarni, J. S.; Crowley, T. A.; Ryan, K. M.; Morris, M. A.; Erts, D.; Holmes, J. D. J. Mater. Chem. 2004, 14, 585.

100. Ziegler, K.; Ryan, K. M.; Rice, R.; Crowley, T.; Erts, D.; Olin, H.; Patterson, J.; Spalding, T. R.; Holmes, J. D.; Morris, M. A. Faraday Discuss. 2004, 125, 311.

101. Erts, D.; Polyakov, B.; Saks, E.; Olin, H.; Ryen, L.; Ziegler, K.; Holmes, J. D. In Functional Nanomaterials for Optoelectronics and Other Applications 2003; Vol. 99-100, p 109.

102. Yu, J. C.; Wang, X. C.; Wu, L.; Ho, W. K.; Zhang, L. Z.; Zhou, G. T. Adv. Func. Mater. 2004, 14, 1178.

103. Waters, J. P.; Smyth-Boyle, D.; Govender, K.; Green, A.; Durrant, J.; O'Brien, P. Chem. Vapor. Depos. 2005, 11, 254.
104. Cohen, Y.; Landskron, K.; Tetreault, N.; Fournier-Bidoz, S.; Hatton, B.; Ozin, G. A. Adv. Func. Mater. 2005, 15, 593.

105. Xiong, C. R.; Balkus, K. J. Chem. Mater. 2005, 17, 5136.

106. Perez, M. D.; Otal, E.; Bilmes, S. A.; Soler-Illia, G.; Crepaldi, E. L.; Grosso, D.; Sanchez, C. Langmuir 2004, 20, 6879.

107. Shi, K. Y.; Chi, Y. J.; Yu, H. T.; Xin, B. F.; Fu, H. G. J. Phys. Chem. B 2005, 109, 2546.

108. Gu, J. L.; Shi, J. L.; Chen, H. R.; Xiong, L. M.; Shen, W. H.; Ruan, M. L. Chem. Lett. 2004, 33, 828.

109. Kim, M. H.; Kwon, Y.-U. Solid State Phenom. in press.

110. Lee, U.-H.; Lee, J.; Jung, D.-Y.; Kwon, Y.-U. Adv. Mater., submitted.

111. Lee, U.-H.; Park, J. B.; Kim, S.-K.; Kwon, Y.-U. NANO, in press. 